Çukurova Üniversitesi Mühendislik Mimarlık Fakültesi Dergisi, 33(3), ss. 23-30, Eylül 2018

Çukurova University Journal of the Faculty of Engineering and Architecture, 33(3), pp. 23-30, September 2018

\title{
Sinyal Emici Metamalzeme Tabanlı Fonksiyonel Basınç ve Yoğunluk Sensörü Tasarımı
}

\author{
Erkan TETİK ${ }^{*}$, Utku ERDIVEN ${ }^{2}$ \\ ${ }^{1}$ Uşak Üniversitesi, Eğitim Fakültesi, Bil. ve Öğretim Tek. Ĕgitimi, Uşak \\ ${ }^{2}$ Çukurova Üniversitesi, Fen Edebiyat Fakültesi, Fizik Bölümü, Adana
}

Geliş tarihi: 15.03.2018 Kabul tarihi: 15.10 .2018

$\ddot{\mathbf{O z}}$

$\mathrm{Bu}$ çalışmada sinyal emici metamalzeme tabanlı fonksiyonel sensör tasarımı yapılmıştır. MTM yapı tasarlandıktan sonra, yapıya farklı kalınlıklarda hava entegre edilmiştir. Bu sayede entegre basınç sensör tasarımı oluşturulmuştur. Daha sonra benzer şekilde MTM yapıya farklı dielektrik sabitine sahip arlon yapılar entegre edilmiştir. Oluşturulan bu entegre yapı ile yoğunluk sensör tasarımı elde edilmiştir. Yapılan hesaplamalarda önerilen sinyal emici MTM 5,2 GHz kablosuz iletişim frekansında mükemmel emilime sahip olduğu görülmüştür. Bu yapıya hava katmanı eklendiğinde, rezonans frekansında kaymalar meydana gelmiştir. Bu önerilen yapının basınç sensörü olarak kullanabileceğini göstermektedir. Benzer şekilde farklı arlon malzemeler eklendiği zaman ise yoğunluk ile ters orantılı olarak rezonans frekansında yine kaymanlar oluşmuştur. Frekansta meydana gelen bu kaymalar önerilen ikinci yapının yoğunluk sensörü olarak kullanabileceğini göstermektedir. Böylece önerilen MTM yapının basınç ve yoğunluk sensörünün gerekli olduğu bir çok uygulamada kullanılabileceği gözlenmiştir.

Anahtar Kelimeler: Metamalzemeler, Sinyal emilimi, Basınç sensörü, Yoğunluk sensörü

\section{Functional Pressure and Density Sensor Design Based on Metamaterial Absorber}

\begin{abstract}
In this study, metamaterial absorber based functional sensors were designed. After the design, air was integrated to the structure and integrated pressure sensor was designed. Similarly, arlon materials with different dielectric constants were integrated to the MTM structure. With the integrated structures created, density sensor designs were obtained. It was observed from the calculations that the proposed MTM absorber has a perfect absorbance value at a frequency of 5,2 GHz wireless communication frequency. With the integration of air layer, shifts at resonance frequency was occurred. This shows that the proposed structure can be used as a pressure sensor. Similarly, with the integration of different arlon materials, shifts at resonance frequencies were observed inversely proportional to density. These shifts show that the structure proposed secondarily can be used as a density sensor. It was observed that the MTM structures proposed can be used for the applications of pressure and density sensors.
\end{abstract}

Keywords: Metamaterials, Absorber, Pressure sensor, Density sensor

\footnotetext{
*Sorumlu yazar (Corresponding author): Erkan TETiK, erkan.tetik@usak.edu.tr
} 


\section{GíRiș}

Metamalzemeler (MTM) doğada bulunmayan olağan dişı özelliklere sahip periyodik olarak tasarlanan yapay elektromanyetik (EM) yapılar olarak tanımlanmaktadır. MTM'lerle ilgili ilk teorik çalışmalar 1968 yılında Veselago [1] tarafından yapılmıştır. Veselago çalışmasında, malzemelerin EM özelliğini belirten bağıl dielektrik sabiti $(\varepsilon)$ ve manyetik geçirgenlik $(\mu)$ parametrelerinin belirli bir frekans aralığında negatif olması durumunda, ortamın da negatif kırılma indisli olabileceği teorisini ortaya koymuştur. Daha sonra, 1996 ve 1999 yıllarında Pendry ve arkadaşları [2-4] Veselago'nun teorik olarak ortaya koyduğu çalışmasını doğrulamak için deneysel bir çalışma yapmışlar ve bu parametrelerin eş zamanlı olarak negatif olabileceklerini göstermişlerdir. Devam eden yıllarda, araştırmacılar bilim ve teknolojide ihtiyaç duyulan MTM tabanlı fabrikasyon metot ve uygulamalara odaklanmaya başlamışlardır [5-7]. Negatif kırılma indisi, grup hızı ve VavilovCerenkov etkisi gibi benzersiz özelliklerinden dolayı MTM'lerin popülerliği hızlı bir şekilde artmıştır. Son yıllarda, sensör [8,9], sinyal emilimi [10,11], anten [12-14], süperlens [15], enerji toplama [16-18] ve pelerinleme [19] gibi bir çok uygulama alanında araştırma konusu olmaktadır. Ayrıca MTM'ler bir çok çalışmada araştırılan mükemmel sinyal emici özelliğe sahiptirler [20-22].

MTM çalışmalarının pek çoğunda negatif kırınım özelliğine sahip malzemenin oluşturulması için $\varepsilon(\omega)=\varepsilon_{1}+\mathrm{i} \varepsilon \quad$ ve $\mu(\omega)=\mu_{1}+\mathrm{i} \mu_{2} \quad$ değerlerinin reel kısmına odaklanılmıştır. Bununla birlikte, optik sabitlerin $\left(\varepsilon_{2} \quad\right.$ ve $\left.\mu_{2}\right)$ göz ardı edilen kayıp bileşenleri, sıra dışı ve kullanışlı malzemelerin olușturulması için oldukça fazla potansiyele sahiptir. Örneğin, bu malzemeler mükemmel seviyede sinyal emici özelliğe sahip yapılar oluşturmak için kurgulanabilir. Sinyal emici MTM (SEMTM) kavramı Landy ve arkadaşları tarafından 2008 yılında ortaya atıldıktan sonra, son yıllarda araştırma alanı olarak oldukça fazla ilgi görmektedir [23]. SEMTM'lerle mikrodalga, terahertz, kızıl ötesi ve optik frekans alanlarıyla ilgili bir çok çalışma yapılmaktadır [24-27]. SEMTM'ler genellikle gelen elektrik alanı emmek için metalik elektrik rezonatörleri kullanılarak oluşturulmaktadır. Gelen manyetik alanı emmek için ise metalik plaka katmanları kullanılmaktadır. Genel olarak üç katmandan oluşan SEMTM'leri oluşturmak için bazı özel şartları sağlamak gerekmektedir. $\mathrm{Bu}$ bağlamda, büyük dielektrik kayıp tanjantı $\delta \varepsilon$, büyük manyetik kayıp tanjantı $\delta \mu$, $\varepsilon(\omega)$ ve $\mu(\omega)$ parametreleri dikkate alınarak, elektrik rezonatör ile plaka katmanlar arasındaki mesafe ve metalik elektrik rezonatörün boyutları ayarlanır. Böylelikle oluşturulan SEMTM gelen EM dalganın tamamını emebilir. Bu mekanizma başta empedans eşleme olmak üzere bir çok model ile açıklanmıştır. Empedans eşleme mekanizmasında, üç katmanlı yapı frekans bağımlı efektif dielektrik sabiti $\varepsilon_{\text {eff }}(\omega)$ ve efektif manyetik geçirgenlik $\mu_{\text {eff }}(\omega)$ ile homojen bir ortamdan yapılan ince bir plak olarak düşünülmektedir. Mükemmel soğurma frekansında $\left(\omega_{0}\right), \varepsilon_{\text {eff }}(\omega)$ ve $\mu_{\text {eff }}(\omega)$ aynı değere ulaşır yani $\left.\varepsilon(\omega)\right|_{\omega=\omega_{0}}=\left.\mu_{\text {eff }}(\omega)\right|_{\omega=\omega_{0}}$ olur ve de empedans boş uzayda $\left.\quad z_{\text {eff }}(\omega)\right|_{\omega=\omega_{0}}=z_{\text {eff }}^{\prime}\left(\omega_{0}\right)+z_{\text {eff }}^{\prime \prime}\left(\omega_{0}\right)=1$ olarak eşleşmiş olur. Aynı zamanda, efektif kırılma indisi $\mathrm{n}_{\text {eff }}(\omega), \omega=\omega_{0}$ iken sanal kısmı oldukça büyük bir değere sahip olur yani $n_{\text {eff }}^{\prime \prime}\left(\omega_{0}\right) \gg n_{\text {eff }}^{\prime}\left(\omega_{0}\right)$ olur ve böylece gelen EM dalga herhangi bir yansıma yapmaksızın SEMTM'ye girer ve onun içinde tamamen sıfırlanır [28]. Sonuç olarak mükemmel soğurma kapasitesine sahip malzemeler elde edilmiş olur.

SEMTM'ler istenilen frekans aralıklarında kablosuz algılama tekniklerinin gerektiği uygulamalar için oldukça uygun bir alt yapı sunmaktadır. Bu algılama teknikleri yer gözlemi ve hava trafik kontrol sistemleri gibi bir çok alanda sensör ve çoklu sensör uygulamaları olarak etkili bir şekilde kullanılabilir [29-31]. MTM sıra dış1 özelliklerinin sensörlerle birlikte kullanılması önemli bir araştırma alanı haline gelmiştir. Mikrodalga tabanlı MTM sensörler yüksek frekanslarda küçük dalga boyları ile küçük ölçeklerde bir çok organik malzemeye tepki vermektedir. Basit bir tasarıma sahip olan MTM'lerin geometrisinde yapılan basit değişikliklerle istenilen frekans aralıklarında ayarlamalar yapılabilir ve farklı alanlarda kullanılan sensörler oluşturulabilir. Bu çalışmada, tasarlanan 
mükemmel emilime sahip MTM kullanılarak mikro dalga frekans aralıklarında mükemmel soğurmaya sahip SEMTM oluşturulmuştur. Öncelikle önerilen yapının iletim ve yansıma değerleri elde edilmiştir. Uygun değerler elde edildikten sonra basınç ve yoğunluk sensörü tasarımları yapılmış ve bu sensörlerin çalışma performansı hesaplanmıştır.

\section{TASARIM PROSEDÜRÜ}

Çalışmanın temel amacı basit bir tasarıma sahip MTM yapılar kullanılarak çok fonksiyonlu algılama özelliklerine sahip yapılar tasarlamaktır. Basınç ve yoğunluktaki değişiklikler önerilen malzemenin elektriksel özelliklerine göre belirlenmektedir. Bu bakımdan önerilen yapının tasarımı ve algılama sonuçlarındaki doğrusallık bu alanda yapılacak çalışmalar için örnek teşkil edip oksijen sensörü gibi ileri düzey araştırmalar için temel oluşturacak niteliğe sahiptir. Önerilen yapının mimarisi iki dielektrik plaka arasına sıkıştırılmış bir sensör tabakasından oluşan sandviç yapı olarak tanımlanmaktadır. Dielektrik plakaların arka yüzeyi elektromanyetik dalga iletimini önleyip maksimum emilim değerini elde etmek için metal bir tabaka ile kaplanmaktadır. Şekil 1(a)'da tasarlanan yapının önden yüzü görülmektedir. Şekil 1(b)'de yapının soldan görünümü yer almaktadır. Şekil 1(c)'de ise araya yerleştirilen sensör katmanı görülmektedir. Sensör katmanını yerleștirmek için rezonatörden sonra öncelikle dielektrik tabaka eklenmiş ve de iki dielektrik tabaka arasına farklı ölçülere sahip sensör katmanı yerleştirilmiştir. Böylelikle MTM tabanlı sensörün tasarımı elde edilmiştir. Aradaki sensör katmanının türü değiştirilerek farklı sensör türleri elde edilebilmektedir.

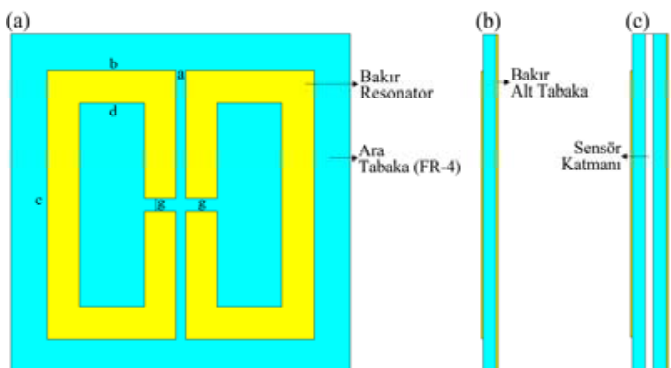

Şekil 1. (a) Önerilen yapının önden görünümü, (b) soldan görünümü ve (c) yapıya sensör katmanının eklenmesi
Tasarlanan yapılarda kullanılan metal plaka ve rezonatörler elektriksel iletkenliği $5,80001 \times 10^{7} \mathrm{~S} / \mathrm{m}$ ve $0,035 \mathrm{~mm}$ kalınlığa sahip olan bakır iletkenlerden oluşmaktadır. Dielektrik katman FR-4 türü malzemelerden oluşmakta ve bu malzeme sırasıyla 1,6 mm kalınlık, 4,3 dielektrik geçirgenlik, 1 manyetik geçirgenlik ve 0,02 kayıp tanjant değerlerine sahiptir. MTM yapının tamamı 42x42 mm ölçüye sahiptir. Rezonatör ise 33x33 mm ölçüye sahip iki parçadan oluşmakta olup bu parçalar birbirlerinin ayna görünümüdür. $\mathrm{Bu}$ iki parçanın arasındaki mesafe $\mathrm{a}=1,6 \mathrm{~mm}$ uzunluğundadır. Rezonatörün geometrik ölçüleri sirasiyla $b=15,7, \quad c=33, d=8$ ve $g=1,7 \mathrm{~mm}$ şeklindedir. Sensör katmanının kalınlığı sensörün hassasiyetini belirlemek için 0,2 ve $1,0 \mathrm{~mm}$ aralığında değişebilecek şekilde tasarlanmıştır.

\section{NÜMERÍK ÇALIŞMA VE ANALİZ}

EM dalga bir nesneye çarptığında nesnenin yapı ve tasarımına göre göre emilebilir, yansıyabilir ve de iletilebilir. $\mathrm{Bu}$ dalganın frekans aralığındaki durumu emilip emilmediğini ya da yansıyıp yansımadığını göstermektedir. $\mathrm{Bu}$ bağlamda, emilim doğrudan yansıma $\left(\mathrm{S}_{11}\right)$ ve iletim $\left(\mathrm{S}_{12}\right)$ katsayılarıyla ilișkili olup açısal $(\omega)$ frekansın bir fonksiyonu olan $A(\omega)=1-\left|S_{11}\right|^{2}-\left|S_{12}\right|^{2}$ formülü kullanılarak hesaplanabilmektedir. Yapının arka kısminda yer alan metal plaka tüm iletimi engellediği için, emilim değeri yalnızca yansıma katsayısına bağlı hale gelmektedir. $\mathrm{Bu}$ durumda emilim formülü $A(\omega)=1-\left|S_{11}\right|^{2}$ şeklinde yazılabilir ve bu denklemden maksimum emilim elde etmek için yansıma katsayısının en aza indirgenmesi gerektiği ortaya çıkmaktadır. Bu koşul ancak boş uzayda gelen sinyalin empedansiyla tasarlanan yapının empedansının eşleştirilmesiyle mümkün olmaktadır. Böylelikle empedans uyumunun sağlanması ve metal plaka ile iletimin engellenmesi şartlarının yerine getirilmesiyle mükemmel bir emilim sağlanabilir.

Yapının tasarımı, hesaplamaları ve analizi CST Microwave Studio programı kullanılarak gerçekleştirilmiştir. Simülasyon çalışmasında, $\mathrm{x}$ ve y doğrultusu mükemmel elektriksel iletken (PEC) sınır şartı, z doğrultusu ise açık sınır şartı olarak 
seçilmiştir. Bu sınır şartları uygulanan dalganın TE polarize dalga olmasını gerektirmektedir. Önerilen yapının ölçüleri parametrik bir çalışma ile belirlenmekte ve iletişim bandında en iyi emilim değerini elde etmek için optimize edilmektedir. Optimizasyon sonuçlarına göre elde edilen yapının frekansa bağlı emilim değerleri Şekil 3'te verilmektedir.
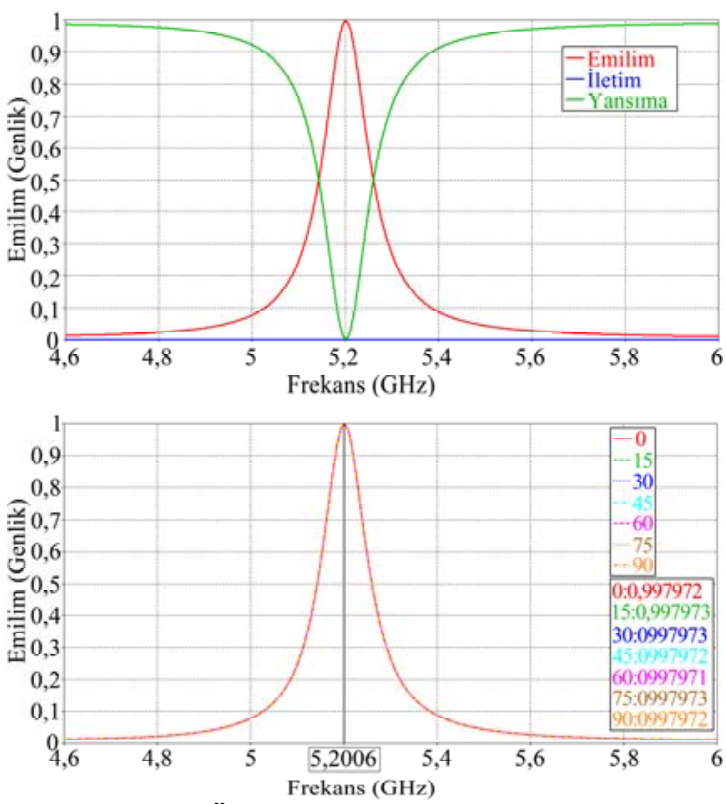

Şekil 2. (a) Önerilen yapının frekans-emilim grafiği ve (b) frekans emilim değerlerinin farklı polarizasyon açılarına göre değişimi

Şekil 2(a)'da frekansın 5,2 GHz iletişim bandında pik yaptığını görülmekte olup, iletim beklendiği gibi tüm frekanslarda 0 değerini almıştır. $\mathrm{Bu}$ sonuçlardan çift rezonatörlü yapının mükemmel bir emilim değerine (\%99,79 civarında) sahip olduğu anlaşılmaktadır. $\mathrm{Bu}$ sonuca göre önerilen yapı mükemmel emilime sahip MTM olarak tanımlanabilir. Sonraki adımda, yapının emilim karakteristiği üzerine gelen dalganın etkisi nümerik olarak analiz edilmiş̧ir. Polarizasyon açısı $0^{\circ}$ ile $90^{\circ}$ arasında $15^{\circ}$ aralıklarla artırılarak her bir açı değeri için frekans emilim grafiği elde edilmiştir (Şekil 2(b)). Bu grafik sonucundan yapının polarizasyon açısından bağımsız olduğu görülmektedir.

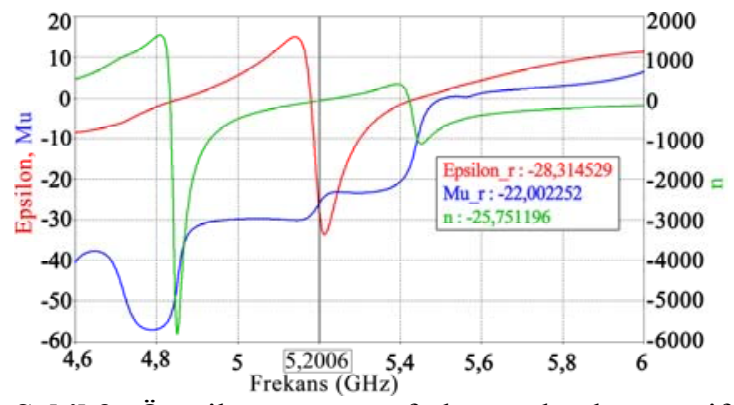

Şekil 3. Önerilen yapının frekansa bağlı negatif dielektrik sabiti, manyetik geçirgenlik ve kırlma indisi grafikleri

Şekil 3'te önerilen yapının frekansa bağlı olarak negatif dielektrik sabiti $(\varepsilon(\omega))$, manyetik geçirgenlik $(\mu(\omega))$ ve kırılma indisi grafikleri yer almaktadır. Grafik sonuçlarına göre, $\varepsilon(\omega), \mu(\omega)$ ve kırılma indisi değerleri sırasıyla $-28,314529$, $-22,002252$ ve $-25,751196$ değerlerine sahiptir. Bu değerler reel kısma göre elde edilmiş olup MTM yapılarda olması gereken negatif değerleri sağlamaktadır. Yapının eş zamanlı olarak negatif dielektrik sabiti ve manyetik geçirgenliğe sahip olmasiyla negatif indeksli periyodik bir ortam oluşturduğu anlaşılmaktadır. Dolayısıyla, önerilen yapı 5,2 GHz iletişim bandında sensör olarak kullanılabilme özelliğine sahip olur.

\subsection{MTM Tabanlı Basınç Sensörü Tasarımı}

Bu bölümde önerilen MTM tabanlı yapının sensör katmanı Şekil 1(c)'de gösterildiği gibi iki dielektrik katman arasındaki bölmeye yerleştirilmiştir. Daha sonra hava boşluğu olarak ayarlanan bu katman belirli aralıklarda arttırılmıştır. Bu yapı üzerinde yapılan uygun ayarlamalarla hava boşluğu basınç seviyesine bağl1 olarak değişim gösterdiği gözlenmiştir. Dolayısıyla, basınç algılama işlemi yapının ön ve arka katmanları arasındaki uzaklıkları izleyerek gerçekleştirilebilir. Yapının bir tarafının farklı basınç değerleri altında hareket edebileceğini dikkate almak suretiyle, yüksek basınç değerleri mesafeyi kısaltırken düşük basınç değerleri iki taraf arasındaki mesafenin artmasına neden olacaktır. Diğer bir deyişle, dar hava boşluğu yüksek basınçları ve geniş hava boşluğu düşük basınç seviyelerini gösterecek olup basınç değerlerinin 
katmanlar arasındaki hava boşluğu mesafesine göre algılanabileceği sonucuna varılmaktadır. Hava boşluğunun kalınlığında yapılan değişiklikler rezonans frekansında doğrusal kaymalar meydana getirmektedir.
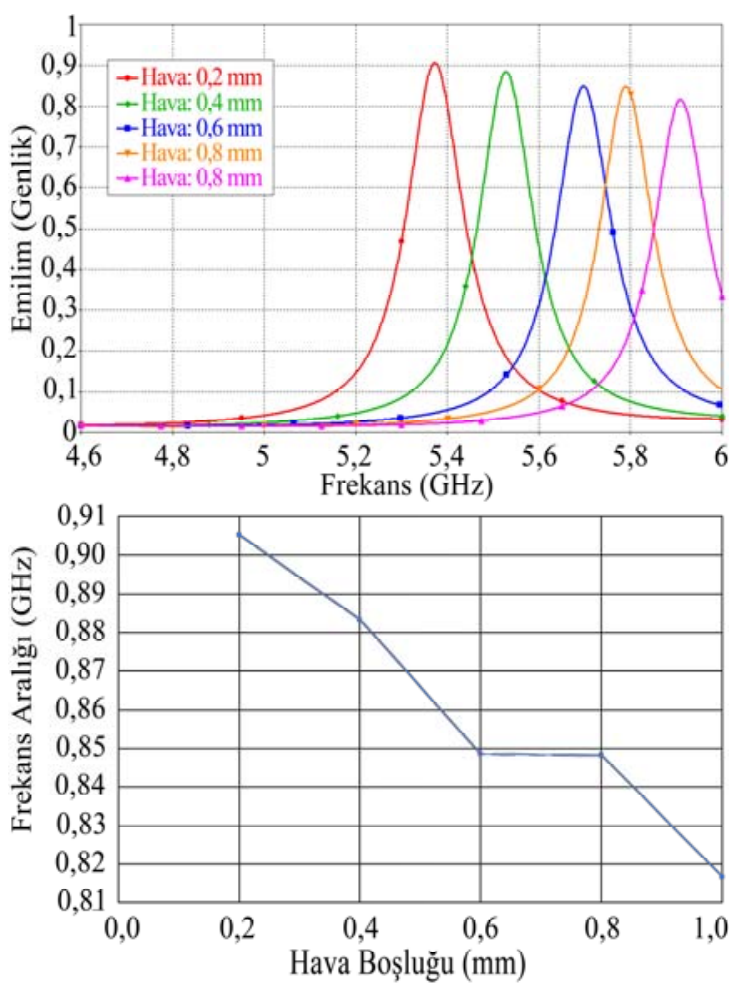

Şekil 4. (a) Önerilen yapıya hava katmanı eklenerek oluşturulan basınç sensör grafiği ve (b) hava katmanı kalınlığının frekansa bağlı değişimi

Rezonans frekansındaki kaymaları gözlemlemek için iki dielektrik katman arasındaki hava boşluğu 0,2 mm uzunluktan $1 \mathrm{~mm}$ uzunluğa kadar 0,2 mm aralıklarla arttırılmıştır. Önerilen MTM tabanlı sensör için yapılan hesaplamalarda sirasiyla 0,2 , $0,4,0,6,0,8$ ve $1 \mathrm{~mm}$ uzunluğa sahip hava boşluğu kullanılmıştır. Elde edilen frekans emilim grafiği Şekil 4(a)'te görülmektedir. Bu grafikten de görüldüğü gibi sensör katmanının her bir kalınlık değerine 5,3728, 5,5282, 5,6976, 5,7900 ve 5,9090 GHz frekans değerleri karşılık gelmektedir. Dikkat edilmesi gereken bir diğer detay ise sensör katmanının kalınlığı arttıkça rezonans frekansının daha yüksek frekanslara kaymasıdır. Bu kayma boşluk kalınlığı ile ters orantılı olan kapasitif etkiden kaynaklanmaktadır. Çünkü hava boşluğunun kalınlığının artması yapı üzerinden EM dalganın daha fazla yol kat etmesi anlamına gelmektedir. Önerilen yapı doğrusal bir frekans tepkisi vermekle kalmaz aynı zamanda her bir sensör kalınlığı için oldukça iyi bir emilim de sağlar. Bu bağlamda, önerilen yapı yüksek doğruluk ve hassaslıkta bir basınç sensörü olarak potansiyel kullanım alanlarına sahiptir denilebilir. MTM tabanlı sensör, basınç algılama uygulaması için neredeyse doğrusal tepki vermektedir. Sensör tabakasındaki basınç düştükçe, hava boşluğu kalınlığı artmakta ve rezonans frekansı değeri de azalmaktadır. Bu durum Şekil 4(b)'de verilen basınç ve rezonans frekansı arasındaki lineer ilişkiden görülmektedir.

\subsection{MTM Tabanlı Yoğunluk Sensörü Tasarımı}

Çalışmanın bu bölümünde arlon AD 350A, arlon AD 450, arlon AD 600 ve arlon AD 1000 dielektrik katmanları yoğunluk algılama sensörü olarak önerilen MTM yapıya entegre edilmiştir. Tasarım basınç sensöründeki tasarıma benzer olarak dizayn edilmiştir. $\mathrm{Bu}$ kısımda kullanılan, farklı türdeki arlon dielektrik katmanının özellikleri Çizelge 1'de verilmektedir. Kompleks elektriksel geçirgenlik değeri Kayıp Tanjantı $=\varepsilon / \varepsilon$ formülü ile hesaplanmıştır. Önerilen yapının rezonans frekans değerleri kapasitans değerine göre değişiklik gösterdiği için, sensör katmanının kalınlığı yoğunluğa göre farklı dielektrik geçirgenlik özelliklerine sahip materyaller kullanılarak tasarlanmıştır. Yapılan optimizasyon çalışmaları ile yoğunluk sensörü için kullanılacak arlon materyali için en uygun kalınlık değeri 0,2 mm olarak elde edilmiştir. Yapı bu kalınlık değeri için en iyi emilim değerine sahip olmaktadır. Bu bakımdan tüm arlon materyalleri için $0,2 \mathrm{~mm}$ kalınlıkta FR-4 materyalinden oluşan iki dielektrik katmanı arasına yerleştirilerek önerilen yapı tasarlanmıştır. Ek olarak, sensör mikrodalga temelli olduğundan algılama katmanlarının elektriksel özellikleri simülasyon çalışmalarıyla belirlenmiştir. 
Çizelge 1. Yoğunluk algılama sensörü olarak kullanılan dielektrik katmanının özellikleri

\begin{tabular}{|c|c|c|c|c|}
\hline $\begin{array}{c}\text { Dielektrik } \\
\text { Katman1 }\end{array}$ & $\begin{array}{c}\text { Yoğunluk } \\
\left(\mathrm{g} / \mathrm{cm}^{3}\right)\end{array}$ & $\varepsilon^{\prime}$ & $\varepsilon^{\prime \prime}$ & $\begin{array}{c}\text { Kayıp } \\
\text { Tanjant }\end{array}$ \\
\hline $\begin{array}{c}\text { Arlon AD } \\
\text { 350A }\end{array}$ & 2,1 & 3,5 & 0,0105 & 0,0030 \\
\hline $\begin{array}{c}\text { Arlon AD } \\
450\end{array}$ & 2,5 & 4,5 & 0,0157 & 0,0035 \\
\hline $\begin{array}{c}\text { Arlon AD } \\
600\end{array}$ & 2,5 & 6.15 & 0,0184 & 0,0030 \\
\hline $\begin{array}{c}\text { Arlon AD } \\
1000\end{array}$ & 3,2 & 10.2 & 0,0234 & 0,0023 \\
\hline
\end{tabular}

Simülasyon çalışmaları Çizelge 1 'de verilen dielektrik malzemeler için yapılmış olup elde edilen emilim frekans grafiği Şekil 5(a)'da verilmektedir. Farklı türdeki arlon tabanlı malzemelerin rezonans frekans1 değerleri sirasıyla 5,0970, 5,0704, 5,0550 ve $5,0340 \mathrm{GHz}$ olarak elde edilmiştir. Rezonans frekansında dielektrik malzemenin türüne bakılmaksızın oldukça iyi emilim değerleri elde edildiği görülmektedir. Emilim değerleri tüm malzemeler için $\% 90$ üzeri değere sahiptir. Şekil 5(a)'daki pik noktalarındaki pik değerleri incelendiğinde, dielektrik katmanına ait dielektrik geçirgenliğin gerçek kısmı arttığında rezonans frekansının da daha düşük değerlere kaydığı görülmektedir. Yapısal kapasitans dielektrik katmanının geçirgenliğinin gerçek kısmı ile doğrudan orantılı olduğu dikkate alındığında, bu kaymaya da kapasitif etkinin sebep olduğu anlaşılmaktadır.

Yoğunluk sensörü çalışması ile ilgili olarak, yoğunluk $\left(\mathrm{g} / \mathrm{cm}^{3}\right)$ değerlerinin dielektrik sabiti ve rezonans frekansı grafikleri Şekil 5(b)'de verilmektedir. İlk kısımda, arlon malzemelerin yoğunluk değerinin rezonans frekansına karşılık gelen değerleri görülmektedir. $\mathrm{Bu}$ değerlerden yoğunluk arttıkça rezonans frekansının düşük değerlere kaydığı görülmektedir. İkinci kısımda ise, yoğunluk değerlerinin dielektrik sabitine karşılık gelen değerleri görülmektedir. Buradan da yoğunluğun artmasıyla dielektrik sabitinin de arttı̆g 1 görülmektedir. Rezonans frekansındaki kaymalardan ve yoğunluk değerlerinin lineer grafik sonuçlarından arlon tabanlı olarak oluşturun MTM yapının yoğunluk sensör olarak kullanılabileceği görülmektedir. Özellikle arlon malzemenin farklı türlerinin oluşturduğun mükemmel emilim değerleri yapının olukça iyi bir algılama kapasitesine sahip olabileceğini göstermektedir.

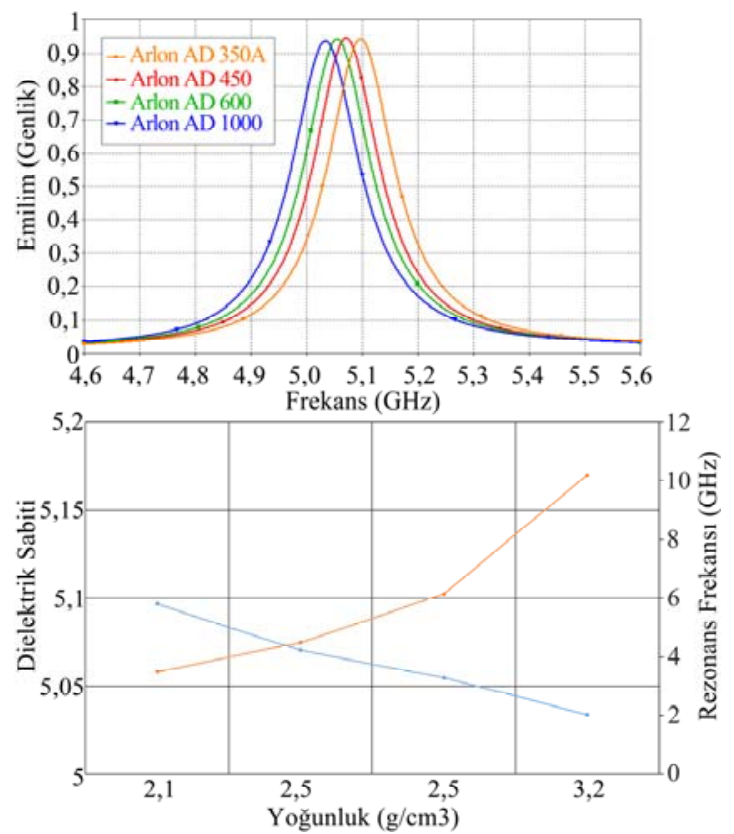

Sekil 5. (a) Önerilen yapıya arlon malzeme eklenerek oluşturulan yoğunluk sensör grafiği ve (b) arlon yoğunluğunun dielektrik sabiti ve rezonans frekansına bağlı değişimi

\section{SONUÇ VE ÖNERILER}

$\mathrm{Bu}$ çalışmada 5,2 $\mathrm{GHz}$ frekans bandında MTM tabanlı sinyal emici sensör tasarımı incelenmiştir. Önerilen yapıda \%99,79 civarında mükemmel düzeyde sinyal emilimi gözlenmiştir. İlk aşamada, MTM tasarımına farklı kalınlıkta hava yapısı entegre edilmiş ve basınç sensörü özellikleri analiz edilmiştir. Elde edilen sonuçlara göre, hava katmanının kalınlığı arttıkça yapının rezonans frekansında kaymalar meydana gelmiştir. $\mathrm{Bu}$ kaymalar kalınlık artışına bağlı kapasitif etkiden kaynaklanmaktadır. Hava kalınlığı arttıkça frekansta kaymalar atmakta, fakat aynı zamanda rezonans frekansının genliğinde düşüş gözlenmektedir. Bu durumda ideal bir sensör için 
0,6 mm kalınlık tercih edilebilir. Böylelikle, önerilen yap1 yüksek doğruluk ve hassaslıkta bir basınç sensörü olarak potansiyel kullanım alanlarına sahiptir denilebilir. İkinci aşamada ise önerilen aynı yapıya farklı özellikler sahip arlon malzemeler entegre edilmiştir. Arlon tabanlı MTM ile yoğunluk algılama sensörü oluşturulmuş ve özellikleri incelenmiştir. Elde edilen frekans emilim grafiklerine göre, yoğunluk arttıkça rezonans frekansının düşük değerlere kaydığı görülmektedir. Kaymalarla birlikte rezonans frekansındaki genlik değerleri birbirine çok yakındır. Oluşan bu kaymalar arlon tabanlı MTM yoğunluk sensörünün farklı malzemeler için verimli bir şekilde çalışabileceğini göstermektedir. Ek olarak, frekansta meydana gelen kaymalara rağmen her iki yapının emilim seviyesi \%80'nin üzerinde kalmıştır. Bu da her iki sensörün oldukça iyi bir emilim düzeyine sahip olduğunu göstermektedir. Sonuç olarak, önerilen MTM tabanlı sensör, basınç ve yoğunluk sensörünün gerekli olduğu bir çok uygulamada kullanılabilir.

\section{TEŞEKKÜR}

Bu çalışma Uşak Üniversitesi Bilimsel Araştırma Projeleri Birimi tarafından desteklenmiştir (Proje no: 2018/SOSB003).

\section{KAYNAKLAR}

1. Veselago, V.G., 1968. Electrodynamics of Media with Simultaneously Negative Electric Permittivity and Magnetic Permeability, Physics-Uspekhi 10(4), 509-14.

2. Pendry, J., 1996. Extremely Low Frequency Plasmons in Metallic Microstructures, Phys. Rev. Lett. 76, 4773-6.

3. Pendry, J.B., Holden, A., Robbins, D., Stewart, W., 1998. Low Frequency Plasmons in Thin Wire Structures, J. Phys. Condens. Matter 10(22), 4785.

4. Pendry, J.B., 2000. Negative Refraction Makes a Perfect Lens, Phys. Rev. Lett. 85(18), 3966-9.

5. Smith, D.R., Padilla. W.J., Vier. D.C., NematNasser, S.C., Schultz, S., 2000. Composite Medium with Simultaneously Negative Permeability and Permittivity, Phys. Rev. Lett.
84(18), 4184-7.

6. Smith, D.R., Pendry, J.B., Wiltshire, M.C.K., 2004. Metamaterials and Negative Refractive Index, Science 305(5685), 788-792.

7. Sabah, C., 2008. Left-handed Chiral Metamaterials, Cent. Eur. J. Phys. 305(5685), 788-92.

8. Dincer, F., Karaaslan, M., Colak, S., Tetik, E., Akgol, O., Altıntas, O., Sabah, C., 2016. Multiband Polarization İndependent Cylindrical Metamaterial Absorber and Sensor Application, Mod. Phys. Lett. B 30(8), 1650095.

9. Bakır, M., Karaaslan, M., Dincer, F., Delihacioğlu, K., Sabah, C., 2016. Tunable Perfect Metamaterial Absorber and Sensor Applications, Journal of Materials Science: Materials in Electronics 27(11), 12091-12099.

10. Bakır, M., Karaaslan, M., Akgol, O., Altıntaş, O., Unal, E., Sabah, C., 2018. Sensory Applications of Resonator Based Metamaterial Absorber, Optik, 168, 741-746.

11. Akgol, O., Karaaslan, M., Unal, E., Sabah, C., 2017. Implementation of a Perfect Metamaterial Absorber into Multi-functional Sensor Applications, Modern Physics Letters B, 31(15), 1750176.

12. Delihacıŏglu, K., Karaaslan, M., Tetik, E., Ünal, E., Dinçer, F., Karadağ, F., 2013. Low Profile Antenna Radiation Enhancement with Novel Electromagnetic Band Gap Structures, IET Microwaves, Antennas Propag. 7(3), 215-21.

13. Tetik, E., Tetik, G.D., 2017. The Effect of a Metamaterial Based Wearable Microstrip Patch Antenna on Human Body, Can. J. Phys. cjp2017-0755.

14. Yan, S., Vandenbosch, G.A.E., 2016. Radiation Pattern-Reconfigurable Wearable Antenna Based on Metamaterial Structure, IEEE Antennas Wirel. Propag. Lett. 15, 1715-8.

15. Aydin, K., Bulu, I., Ozbay, E., 2007. Subwavelength Resolution with a NegativeIndex Metamaterial Superlens, Appl. Phys. Lett. 90(25).

16. Unal, E., Dincer, F., Tetik, E., Karaaslan, M., Bakir, M., Sabah, C., 2015. Tunable Perfect Metamaterial Absorber Design using the Golden Ratio and Energy Harvesting and Sensor Applications, J. Mater. Sci. Mater. Electron. 26(12), 9735-40. 
17. Zhong, H.T., Yang, X.X., Tan, C., Yu, K., 2016. Triple-band Polarization-insensitive and Wideangle Metamaterial Array for Electromagnetic Energy Harvesting, Appl. Phys. Lett. 109(25).

18. Bağmanc1, M., Karaaslan, M., Ünal, E., Akgol, O., Karadağ, F., Sabah, C., 2017. Broad-band Polarization-independent Metamaterial Absorber for Solar Energy Harvesting Applications, Phys. E Low-Dimensional Syst. Nanostructures 90, 1-6.

19. Schurig, D., Mock, J.J., Justice, B.J., Cummer, S.A., Pendry, J.B., Starr, A.F., Smith, D.R., 2006. Metamaterial Electromagnetic Cloak at Microwave Frequencies, Science 314(5801), 977-980.

20. Akgol, O., Altintas, O, Dalkilinc, E.E., Unal, E., Karaaslan, M., Sabah, C., 2017. Metamaterial Absorber-based Multisensor Applications using a Meander-line Resonator Opt. Eng. 56(8).

21. Ding, F., Cui, Y., Ge, X., Jin, Y., He, S., 2012. Ultra-broadband Microwave Metamaterial Absorber, Appl. Phys. Lett. 100(10).

22. Hao, J., Wang, J., Liu, X., Padilla, W.J., Zhou, L., Qiu, M., 2010. High Performance Optical Absorber Based on a Plasmonic Metamaterial, Appl. Phys. Lett. 96(25).

23. Landy, N.I., Sajuyigbe, S., Mock, J.J., Smith, D.R., Padilla, W.J., 2008. Perfect Metamaterial Absorber, Phys. Rev. Lett. 100(20).

24. Xu, W., Sonkusale, S., 2013. Microwave Diode Switchable Metamaterial Reflector/absorber, Appl. Phys. Lett. 103(3).

25. Chen, H.T., Padilla, W.J., Cich, M.J., Azad, A.K., Averitt, R.D., Taylor, A.J., 2009. A Metamaterial Solid-state Terahertz Phase Modulator, Nat. Photonics 3(3), 148-51.

26. Ginn, J., Shelton, D., Krenz, P., Lail, B., Boreman, G., 2009. Altering İnfrared Metamaterial Performance Through Metal Resonance Damping, J. Appl. Phys. 105(7).

27. Dincer, F., Karaaslan, M., Unal, E., Akgol, O., Sabah, C., 2015. Flexible Chiral Metamaterials with Dynamically Optical Activity and High Negative Refractive Index, Mod. Phys. Lett. B 29(18), 1550087.

28. Tetik, E., 2017. An Overview of Metamaterial Researches, Researches on Science and Art in 21St Century Turkey, Gece Publishing 2, $1817-25$.
29. Boopathi, Rani, R., Pandey, S.K., 2017. Metamaterial-inspired Printed UWB Antenna for Short Range RADAR Applications, Microw. Opt. Technol. Lett. 59(7), 1600-4.

30. Abdalla, M.A., Hu, Z., 2012. On the Study of Development of X Band Metamaterial Radar Absorber, Adv. Electromagn. 1(3), 94-98.

31. Bagmanci, M., Karaaslan, M., Altintas, O., Karadag, F., Tetik, E., Bakir, M., 2018. Wideband Metamaterial Absorber Based on CRRs with Lumped Elements for Microwave Energy Harvesting, 52(1), 45-59. 